\title{
Standing to Epistemically Blame
}

\begin{abstract}
A plausible condition on having the standing to blame someone is that the target of blame's wrongdoing must in some sense be your "business"- the wrong must in some sense harm or affect you, or others close to you. This is known as the business condition on standing to blame. Many cases of epistemic blame discussed in the literature do not obviously involve examples of someone harming or affecting another. As such, not enough has been said about how an individual's epistemic failing can really count as another person's business. In this paper, I deploy a relationship-based account of epistemic blame to clarify the conditions under which the business condition can be met in the epistemic domain. The basic idea is that one person's epistemic failing can be another's business in virtue of the way it impairs their epistemic relationship.
\end{abstract}

\section{Introduction}

When is your epistemic conduct someone else's business? Is it ever anyone else's business? According to Philippe Chuard and Nicholas Southwood, it is not:

[E]pistemic deontic claims don't seem to be interpersonal in the relevant sense [...]. Usually, the expectations of others regarding one's epistemic behaviour are neither here nor there. How we run our epistemic lives is not others' business (Chuard \& Southwood 2009, 623).

This is a striking claim. But it fits with a common attitude in traditional epistemology. Until relatively recently, epistemology has been a thoroughly individualistic enterprise (Goldman \& McGrath 2014, 203). As is often pointed out, we inherited from philosophers such as Descartes and Locke the idea that epistemology is fundamentally first-personal: while other people might play an important role in our practical and moral deliberations, they do not (or cannot) really play an important role in our epistemic deliberations. Outlining the shortcomings of an individualistic approach to epistemology is one focus of the growing field of social epistemology. A lot of great work has been done to this effect (Coady 1992; Goldberg 2010, 2018; Goldman \& Whitcomb 2010). ${ }^{1}$ One cluster of issues that has not been explored in much detail, however, centers on the implications of the individualistic approach for our understanding of epistemic blame.

\footnotetext{
${ }^{1}$ Early precursors to more recent developments in social epistemology include Gilbert Harman's work on the social dimension of epistemic rationality (Harman 1986), and Tyler Burge's work on the social dimension of belief and mental content (Burge 1979; 1986).
} 
These implications come sharply into view when we examine conditions on standing to blame. According to many moral theorists, one condition on having the standing to blame someone is that the target of blame's wrongdoing must in some sense be your "business"the wrong must in some sense harm or affect you or others close to you. This is known as the business condition on standing to blame (Smith 2007; Radzick 2011, 2012; c.f. Bell 2013 and Todd 2017). ${ }^{2}$ If there is a business condition on standing to blame, and if Chuard and Southwood are right — if our epistemic lives are not others' business - it would seem to follow that no one has the standing to epistemically blame anyone else. That would be puzzling. Because we do seem to blame one another from the epistemic point of view. Indeed, epistemic blame has come to play a prominent role in epistemology. ${ }^{3}$

While I think Chuard and Southwood's claim fits with a common attitude in traditional epistemology, I don't think it can be right. It seems that epistemic failings can be the business of other people. However, it is not always obvious when, or why this is the case. This is an important issue, not least because many of the sorts of cases of epistemic blame frequently discussed in the literature are not clear examples of one person harming or affecting another. As such, not enough has been said about how an individual's epistemic failing can really count as another person's business.

My aim in this paper is to fill this lacuna. My strategy is to first outline a relationshipbased framework for thinking about the nature of epistemic blame. According to the framework, epistemic blame, at its core, is a matter of modifications to the intentions and expectations that comprise our "epistemic relationships" with one another (Boult 2020, 2021). I then put the account to work with the aim of clarifying the conditions under which the business condition can be met in the epistemic domain. The basic idea is that one person's epistemic failing can be another's business in virtue of the way it impairs their epistemic relationship. A key issue to examine in this context concerns what entitles us to have the sorts of epistemic expectations that partially comprise our epistemic relationships. I deploy recent work from Sandy Goldberg to help with this question. An interesting upshot of examining standing conditions on epistemic blame is the connection revealed between our understanding of the nature of epistemic blame, and recent work in social epistemology about normative expectations.

Section 2 discusses the business condition on standing to blame in more detail. Section 3 explains why the business condition raises some important questions about epistemic blame. Section 4 introduces the relationship-based framework, and Section 5

\footnotetext{
${ }^{2}$ I make some important qualifications to the business condition in Section 2.

${ }^{3}$ I will be saying more in defense of these claims in Section 3 and Section 6. For skeptics about epistemic blame (Feldman 2004; Papineau 2012; Dougherty 2012, 2014; Kauppinen 2018), this paper can be read as addressing an interesting problem for the significant number of epistemologists who endorse the idea that there is such thing as epistemic blame.
} 
extends the framework to the epistemic domain. Section 6 explains how-with help from Goldberg - the framework can make sense of the business condition on epistemic blame. Section 7 concludes.

\section{Standing to Blame: The Business Condition}

Not just anyone can justifiably blame anyone else, even if the target of blame is blameworthy. A prominent idea is that one needs to meet certain conditions on standing that make blame an appropriate thing to do. ${ }^{4}$ By "standing to blame", I have in mind not merely the standing to express blame, but also to manifest blame itself, whether privately or publicly—for example, whether in the form of feelings, thoughts, speech-acts, or some combination thereof. According to some, a "non-hypocrisy condition" requires that the blamer not manifest the same flaw that they attempt to criticize in another (Fritz \& Miller 2018, 119). Perhaps relatedly, a "non-complicity" condition requires that the blamer not be complicit in the wrongdoing that is the target of their blame (Bell 2013). While each of these conditions would be interesting to explore in the epistemic domain, my focus is the business condition.

There are times when it would seem presumptuous or meddling to blame someone you do not know for a wrongdoing that does not harm or affect you, or others close to you. I am at a party and I see a man I have never met making belittling comments to his partner. According to Angela Smith, "Since I do not know this person, or his wife, an explicit reproach on my part would be presumptuous and meddling, even if critical attitudes toward him are perfectly warranted" (Smith 2007, 478). Whether it is appropriate for me to express blame towards someone seems to depend in part on whether their wrongdoing is my business. It seems to depend on whether, or to what extent, their wrongdoing affects me or others close to me. The question of whether someone's wrongdoing is my business does not merely constrain the appropriateness of expressing blame. It can also constrain the mere adoption of a blaming-attitude or blame-response more broadly. As Smith puts it, "While we may not need any special authority to morally disapprove of another person on the basis of her objectionable attitudes or behavior, it seems that specific sorts of anger, resentment, and disappointment are open only to those directly wronged by the person in question" (2007, 479). ${ }^{6}$

\footnotetext{
${ }^{4}$ As has been widely discussed, considerations of blameworthiness and standing do not settle the question of whether blame is appropriate or justified. There are also instrumental considerations such the consequences that blaming may have on the wrongdoer, or the blamer. I largely set these further considerations to one side for the remainder of this paper.

${ }^{5}$ Not everyone is convinced that "standing" is an important consideration when it comes to determining the appropriateness or justifiedness of blame. See Bell (2013) for a general critique.

${ }^{6}$ Precisely what it takes for one person's wrongdoing to count as another person's "business" has not been spelled out very clearly in the literature. For example, in a paper-length critique of standing conditions, Macalester Bell simply analyzes the notion of "business" as follows: "Y's wrongdoing is
} 
There is some debate about whether the business condition really is a condition on standing to blame, as opposed to a condition on the expression of blame, or anything blamerelated at all. Patrick Todd (2017) has argued that the business condition is not a condition on standing to blame, but rather that it is a condition on standing to express blame (publicly) (cf. Bell 2013). ${ }^{7}$ I have three things to say in response. First, the business condition is considerably more plausible if we take it as regulating the strength or kind of blame that is appropriate in a particular case, as opposed to functioning like an on-off switch. On the strength- or kind-regulating model, the question of whether someone's wrongdoing is your business is a matter of degree, and the strength or kind of blame that may be appropriate covaries in certain ways with the extent to which their wrongdoing is your business (along with other conditions). On the on-off switch model, either someone's wrongdoing is your business or it is not, and the question of whether it would be appropriate to blame them is a "yes" or "no" question, as opposed to one of degree. My point is that the former model is more plausible. ${ }^{8}$

Second, the business condition gains further plausibility if we emphasize an additional distinction beyond that of expressions of blame and blame itself. This is the distinction between blame and negative evaluation (including judgments of

X's business. That is, $\mathrm{X}$ has an identifiable stake in Y's wrongdoing. Let's call this the Business Condition" (Bell 2013, 264). Tognazzini and Coates understand business in terms of an impact on the blamer's life. For example, discussing a case meant to illicit intuitions about the business condition, they invite the reader to compare themselves with a wrongdoer's parents in the following way: "Because of their close relationship, Jennifer's failure has a significant impact on her parents' lives; she has (perhaps) wasted thousands of dollars of their money. By contrast, her failure has little or no impact on our lives" $(2013,21)$. Todd appears to leave the notion of "business" unanalyzed, but does intimate that it has something to do with the "nature of the relationships involved" and "severity of the wrongdoing". He also claims that intuitions surrounding this notion can most easily be solicited by thinking about the "context of intimate relationships (e.g. between parents and children, and romantic partners)" (2). In her defense of something akin to the business condition, Angela Smith (2007) doesn't use the term "business", but she links the closely related idea of meddlesomeness to considerations about whether one knows the wrongdoer: "If I am not a stranger, but close friends with one or both of these people, by contrast, I may have legitimate standing to express criticism in such a case" (2007, 478). She links meddlesomeness to the question of whether the blamer was "directly wronged" by the wrongdoer: "it seems that specific sorts of anger, resentment, and disappointment are open only to those directly wronged by the person in question" $(2007,479)$. But it may be a mistake to think of this as substantively different from an analysis that focuses primarily on the notion of a relationship. For example, many wrongdoings seem to be relationship-specific, in the sense that one is wronged by person X partly in virtue of standing in a certain relationship to X (think of the specific harm an old friend can do to you by failing to attend your wedding without excuse). In a sense, this is just one way of understanding the very idea of being "directly wronged". I take the notions of direct harm, having a stake, and standing in the right relation to someone as an interlinked cluster of ideas which all get at the same basic concept of "business". For purposes of this paper, a more precise analysis of the concept is unnecessary.

${ }^{7}$ Another issue, not discussed by Todd, concerns the question of whether the sort of wrong committed in violating the business condition is moral or prudential in nature (Seim 2019, 12).

${ }^{8} \mathrm{~A}$ different, but related strategy could be to construe the force of the business condition in terms of pro tanto reasons. If someone's wrongdoing is not your business, perhaps this gives you a pro tanto reason to refrain from blaming them-one that can be overridden by other considerations. See Coates 2020 for this formulation of the condition. 
blameworthiness). While it is entirely plausible that we can appropriately negatively evaluate others for wrongdoings that are not our business, it is much less clear whether, or to what degree, blame-responses are appropriate responses to those doings. Perhaps this is because blame has a significance that goes beyond mere negative evaluation. Blamers are somehow engaged by their negative evaluations in a way that makes it less obvious that blame is an appropriate response to a wrongdoing that is not the blamer's business. ${ }^{9}$

Third, on the approach to the nature of blame that I favor (in both its epistemic and moral varieties), there is a natural explanation of why we should expect there to be a business condition on standing to blame (and not just to express blame). I will return to this point below. For the purposes of this paper, I will assume for the sake of argument that the business condition is a genuine condition on standing to blame. ${ }^{10}$

\section{The Business Condition and Epistemic Blame}

The business condition raises some important questions about the increasingly prominent notion of epistemic blame. Epistemic blame is widely taken to be a form of blame done from the perspective of promoting epistemic goods, such as believing truly and avoiding believing falsely. ${ }^{11}$ In all cases of epistemic blame, the target of blame has epistemically failed in some way; the idea is that an epistemic blame response is a blame response to that failing. ${ }^{12}$ Many targets of epistemic blame may also be targets of moral blame, or other kinds of blame. But they need not be. Perhaps partly because epistemic blame need not overlap with moral blame, it is not always clear that the epistemic failings theorists typically focus on in the context of discussing epistemic blame are really cases of one person directly harming or affecting another (or other groups). It is not always clear how cases of epistemic blame involve

\footnotetext{
${ }^{9}$ See Boult 2021 for in-depth discussion of this point.

${ }^{10}$ See Radzik $(2011,2012)$ and Seim (2019) for another defense of the business condition.

${ }^{11}$ Some have defined epistemic blame as a kind of blame that attaches to belief, or other doxastic states, such as disbelief and suspension of belief. This cannot be the whole story, however, since there are cases of blame for doxastic states that seem moral in nature, perhaps in addition to being epistemic. Tara believes there is no point in respecting other people's feelings, simply because she has had enough with the world and doesn't care anymore. She has not yet acted on this belief. But in conversation, her sister Toni learns about this unsettling turn in Tara's moral outlook, and blames her for even thinking this way. It is natural to think of this as a kind of moral blame, as opposed to, or perhaps in addition to, something deserving the title "epistemic blame". There may also be cases of epistemic blame that do not target a person's doxastic states (at least not directly, or primarily). Epistemic blame may target an assertion, someone's actions of inquiry, or a particular inference someone makes.

${ }^{12}$ Is epistemic blame a sui generis response, or simply the same sort of response as moral blame, but directed at agents for their epistemic failings? I am open to different approaches to this question. If we approach the nature of blame in the way I propose in what follows - namely, as a kind of relationshipmodification - then, perhaps in one sense epistemic blame can be understood as the same sort of response as moral blame. It is the same in the sense that they are both forms of relationshipmodification. In another sense, however, the response may be considered sui generis in that the specific kind of relationship-modification involved is importantly different from the kind involved in cases of moral blame. See Sections 5 and 6 for the details of my account.
} 
epistemic failings that are the business of anyone else in this way. At least, the way cases of epistemic blame are presented in the literature often leaves wide open the question of whose business the failing would be, and why. For example, discussions often involve highly abstract descriptions of cases in which someone is guilty of an epistemic failing, and it is said that "we" may blame them for it. Consider Jessica Brown:

For instance, when we blame Maud for dogmatically believing against the evidence that the President is in New York, the frustrated desire that she not believe badly leads to negative feelings such as our anger with her $(2020,11)$.

In the context of discussing the relationship between epistemic blame and doxastic control, Connor McHugh says:

We blame and even resent people, when, for example, they form foolish or hasty beliefs on matters of importance, and when they fail to believe what they should. [...] [W]e often claim that people should not hold or should give up certain beliefs because they are unsupported by evidence; we blame people who hold such beliefs" (McHugh 2012, 66).

The assumption seems to be that at least someone could have the standing to epistemically blame the relevant people under certain conditions. And perhaps that is true enough. But it is interesting to dig deeper and get a better sense of the extent to which this can be the case, and what makes it so.

To be sure, some epistemic failings seem fairly straightforwardly to be the business of specific individuals. After all, there are fairly straightforward ways in which the epistemic failings of others can directly harm us or others close to us. Stephen is applying for a job. Terri, the person interviewing him, happens to have biased beliefs about the work ethic of members of the visible minority that Stephen identifies with. Stephen doesn't get the job. If he somehow learned that the reason he didn't get the job was largely because Terri formed unjustified beliefs about his work ethic, Stephen might blame Terri for her epistemic failing, and it seems he would meet the business condition in doing so.

Cases of someone's epistemic failure leading to a practical harm-a harm done to either yourself or someone close to you-are common. But two points are worth emphasizing. First, it is not clear that the kind of blame that would be fitting, in cases like the Stephen case, is a distinctively epistemic kind of blame. At the very least, it would be nice if we could provide a clear way of explaining what makes this so. Second, there seem to be other kinds of cases in which one person has the standing to epistemically blame another but 
at least one of two things is true: i) no practical harm has been done; ii) the practical harm is not itself what licenses the blame response, or is not the only feature of the case that makes a blame response fitting. Perhaps the following is an example:

The Office: One day while sitting at their desks, Dwight reveals to Jim that he believes there's a conspiracy amongst his coworkers. The aim of this supposed conspiracy is to ensure that Dwight will be laid off in the company's upcoming plans to downsize. Dwight is so convinced, he secretively entreats Jim to form an "alliance" to counteract the efforts of the conspiracy. It doesn't take long for Jim to realize Dwight's conspiracy beliefs are unfounded; he has no evidence in support of them. When Jim realizes this, he criticizes Dwight, quite severely (mainly to himself, but also via certain overt actions, such as requests for reasons- -"how could you think this, Dwight?" - or sighs of exasperation). He criticizes Dwight in a way that goes beyond merely assigning him a bad epistemic grade for his epistemic failing.

We might say that Jim epistemically blames Dwight. After all, he is somehow engaged by a critical attitude he takes toward Dwight, specifically oriented towards Dwight's intellectual conduct. But what more specifically would make this an epistemic kind of blame? And in virtue of what does Jim meet the business condition? My aim in the next few sections is to answer these questions. My strategy is to present an account of epistemic blame, and then argue that it enables us to explain, in a unified way, how the business condition on epistemic blame can be met in a wide variety of cases.

\section{The Relationship-Based Framework}

A general idea in the moral blame literature — defended most explicitly and forcefully by T.M. Scanlon-is that blame should be understood as a kind of relationship-modification. More specifically, the idea is that blame is essentially a kind of modification to one's relations with another person made fitting in response to a judgment that they have somehow impaired those relations.

Scanlon understands relationships as sets of intentions, expectations, and attitudes people have concerning how to act, think, and feel towards one another-intentions, expectations, and attitudes that are justified by a wide range of facts about parties to the relationship, depending on those involved and the kind of relationship it is. Scanlon also draws a distinction between token relationships and relationships as normative ideals. The former are actual relationships people have with one another. The normative ideals of these 
relationships specify idealized sets of intentions and expectations that we might take to constitute normatively good (or best) examples of such relationships.

A useful example is friendship. Other things being equal, being a good friend requires "intending to give help and support when needed, beyond what one would be obligated to do for just anyone; intending to confide in the person and to keep his or her confidences in return; and intending to spend time with the person when one can, and to 'keep in touch"' (Scanlon 2008, 132). ${ }^{13}$ Other things being equal, we expect our friends to do the same for us. Such intentions and expectations comprise a kind of normative ideal of friendship. ${ }^{14}$ In Scanlon's framework, to judge someone blameworthy is to judge that they have done something that indicates they have intentions or attitudes that fall short of such a "normative ideal" of the relevant relationship. It is to judge that the relationship has been impaired in some way. ${ }^{15}$ To blame someone, then, is to judge them blameworthy and to modify one's intentions or expectations towards that person in a way made fitting by this judgment. Lani might judge that her friendship with Lee has been impaired because Lee failed, without excuse, to keep a promise to Lani. A fitting response to this judgment might be for Lani to intend to place less confidence in Lee's word in the future; depending on the severity of the breach of confidence, it might be fitting to stop intending to feel pleasure at Lee's successes in the future, for example, or to cut off relations altogether. According to Scanlon, this combination of judgments, and modifications to intentions and expectations made fitting as a result, just is what Lani's blame consists in.

The framework leaves room for negative emotions which are often associated with blame, such as feelings of indignation and resentment. But it is distinctive in the relative centrality it gives to modifications to our intentions and expectations as opposed to negative emotions. Feelings of indignation and resentment (and other emotions) are of course a regular part of what happens when we blame, but for Scanlon they are not central. Indeed, Scanlon advertises as an advantage of his account that it can accommodate the "coolness" of certain examples of our blaming practices. For instance, we seem sometimes to blame others simply by deciding not to make certain plans with them, or by cutting off relations, or through feeling a sense of sadness. While heated emotional responses need not accompany such attitudes and behaviors, according to Scanlon they can nevertheless be genuine forms of blame. What makes them genuine - and indeed what they have in common with negative emotional

\footnotetext{
${ }^{13}$ In addition to these intentions, in order to count as a good friend one must actually be disposed to behave in these ways, and to do so for the right reasons $(2008,132)$.

${ }^{14}$ In addition to a central core of intentions and expectations that one must have in order to count as a good friend, there are also non-obligatory intentions that are nevertheless good to have according to the normative ideal. Intending to take pleasure in the successes of one's friend, or to generally hope that things go well for them, might be two such examples.

15 The judgment need not be explicitly recognized as such on behalf of the agent to count as the right kind of judgment. This point holds true for my epistemic extension of the relationship-based account.
} 
responses (when the latter function as genuine forms of blame) - is that that they are ways of modifying our relations with others in a way made fitting by a judgment of relationship impairment.

R.J. Wallace (2013) and Susan Wolf (2011) have argued in separate ways that the relationship-based framework is simply too "cool". According to Wallace, for example, reactive attitudes such as indignation and resentment are essential to what it really means to blame someone. The fact that Scanlon's account does not give them a central role is a defect of the account. My approach to this worry is to avoid taking a stand on whether this is true of moral blame. In my view, this is actually an example of how an extension of Scanlon's framework to the epistemic domain seems particularly promising. While reactive attitudes such as indignation and resentment may be integral to moral blame, in my view they do not seem integral to epistemic blame. ${ }^{16}$

There are of course other worries we might have about this general framework. I will address some of the more pressing issues - a number of which seem equally important for an epistemic extension of Scanlon's basic ideas - at the end of the next section. For now, a crucial question needs addressing. How can an epistemic extension of this framework even so much as get off the ground? What, for starters, is the relevant relationship with which we might begin developing an account of epistemic blame? To extend the view, I propose making use of the notion of an "epistemic relationship". ${ }^{17}$

\section{The General Epistemic Relationship}

Let an epistemic relationship be a set of intentions, expectations, and attitudes people have towards one another that are oriented towards their epistemic agency in different ways. Sometimes they are oriented towards cultivating epistemic agency; other times, they are oriented towards utilizing it in more or less specialized ways. In broad outline, my view is that we should understand judgments of epistemic blameworthiness as judgments that someone has fallen short of a normatively idealized set of such intentions and expectations, against which we can measure their epistemic relationship with that person. Epistemic blameresponses can then be understood as modifications to the actual intentions and expectations that one has towards that person, in a way made fitting by this judgment. ${ }^{18}$ Allow me to elaborate.

\footnotetext{
${ }^{16}$ For those who are sympathetic to negative emotional response approaches to blame (perhaps including epistemic blame), it will be important to remember that the framework I will be working with can allow that certain kinds of negative emotion can accompany blame-responses.

${ }^{17}$ The following draws on and further develops work from Boult 2020, and Boult 2021.

${ }^{18}$ The account does not require that ordinary speakers have the concept of an "epistemic relationship", or the concept of an impairment of such a relationship. Rather, the contents of any blame-relevant judgment can be more specific: they can concern failures to conform belief to the evidence, assertions
} 
The division of epistemic labor is a basic fact of human social life. We rely on one another on a near continual basis for information. This is as true for the mundane as it is for matters of great importance. I rely on the stranger sitting next to me for information about when the next bus arrives. I rely on experts for information that will help me decide whether the vaccine is safe. Importantly, I do not merely rely on others for information, in the way that I might rely on an old car that I fear might break down any day. Rather, other things being equal, we tend to have a certain degree of confidence in one another when it comes to our ability to run our intellectual lives. This confidence is partly constituted by a mixture of expectations in both the predictive and normative sense of "expectation". Other things being equal, we tend to expect, in the sense of anticipate it to be the case that, other epistemic agents will meet at least certain minimal criteria in the running of their intellectual lives (for example, they will recognize ordinary mid-sized objects when they can see them in good lighting). But we also expect, in the sense of making a kind of demand, that they will meet certain epistemic criteria in the running of their intellectual lives, sometimes in a way that outstrips our predictive expectations (Goldberg 2015; 2018, Ch.5). In my view, it is in this way that members of an epistemic community stand in a relationship of mutual epistemic expectation - one that is bound up with a complex network of intentions and expectations that are oriented around our epistemic agency in very basic ways. This is what I call the General Epistemic Relationship (GER). There are likely other more specific kinds of epistemic relationship - the relationship between producers and consumers of media might be an example, or the relationship between teachers and students (I return to this point in Section 6) - but for now I will restrict myself to outlining some basic details of the GER.

To help spell out the GER in more detail, I'll introduce one more technical term. This is the notion of an "intellectual act":

Intellectual Act: any attempt at exercising one's epistemic competence, such as: forming a belief that $\mathrm{p}$ (perceptually, inferentially, by memory access, etc.) through one's ability to reliably believe true propositions (perceptual ability, inferential ability, memory ability, etc.); asserting that $\mathrm{p}$ through one's ability to reliably assert true propositions; maintaining a belief that $\mathrm{p}$ through one's ability to reliably maintain true beliefs that $\mathrm{p}$, etc.

I propose that the intentions and expectations that are constitutive of the normative ideal of the GER include the following. When all goes well, for any member A, B:

of falsehoods, etc. These are things that, we will see below, constitute impairments of different sorts of epistemic relationships. 
- A intends, for any intellectual act X of A's, to meet epistemic criteria Y, unless A has good reason not to.

- A expects, for any intellectual act X of B's, that B will meet epistemic criteria Y, unless B has good reason not to.

- B intends, for any intellectual act X of B's, to meet epistemic criteria Y, unless B has good reason not to.

- B expects, for any intellectual act X of A's, that a will meet epistemic criteria Y, unless A has good reason not to.

This is by no means an exhaustive list of the intentions and expectations that may comprise the GER. There are plausibly other intentions and expectations, such as a standing intention to epistemically trust the word of others, under certain conditions, and an expectation that others will epistemically trust one's word under certain conditions. As I understand the term, epistemic trust is not identical to garden variety trust. Often, when we "trust" someone, we understand this to entail, among other things, that we think they do not harbor intentions to deceive or mislead. Epistemically trusting someone, however, entails only that we have confidence that they are a reliable source of information - that believing what they say is a way of arriving at a favorable ratio of true to false beliefs, or knowledge, or understanding, etc. - and that you are willing to rely on them as such. ${ }^{19}$

How do we determine who counts as a member of the epistemic community? How finely grained should our epistemic intentions and expectations be individuated? This is an important question, because people can be highly reliable on one subject matter, while being unreliable on another. These questions can be helpfully addressed in the context of accounting for the business condition on standing to blame, which I turn to next section. For now, it will be useful to point out that we can already make sense of a wide range of cases of epistemic blame. We can do so by endorsing the following general claim:

Epistemic Blame - Generic Type I: One party to the GER can appropriately epistemically blame another for conducting their intellectual lives in a way that gives one a good reason to modify their epistemic relationship with that person, at least within some restricted domain, or on some specific matter. ${ }^{20}$

\footnotetext{
${ }^{19}$ See McCraw (2015), and the more recent Carter and Simion (forthcoming), for helpful discussions of epistemic trust.

${ }^{20}$ I call this "Generic Type I" because there may be other general principles in the ethics of epistemic blame that can be derived from the GER. For example, perhaps sometimes epistemic blame can be appropriately directed at others for perpetrating testimonial injustice (Fricker 2007). The idea would be that, rather than focusing on our expectations of the target of blame, we can also focus on the expectations
} 
As we have seen, people are widely understood to be appropriate targets of epistemic blame for things like dogmatic thinking (Brown 2020, 11), forming "foolish or hasty beliefs on matters of importance", and maintaining beliefs that are unsupported by evidence (McHugh 2012, 66). In my view, these are ways of impairing our epistemic relationships with one another. They are examples of intellectual conduct that tends to give others good reason to modify their epistemic relationship with a person, at least within some restricted domain, or on some specific matter. Thus, according to the relationship-based account of epistemic blame, it is natural to expect that epistemic blame may be an appropriate response to such epistemic failings.

The relationship-based framework - in both its moral and epistemic forms-raises some further questions that will be important to address before moving on to the specific issue of making sense of the business condition in the epistemic domain. For a start, can't there be blame without relationship modification? Consider a husband who fails to bring his partner anniversary flowers for the $7^{\text {th }}$ year in a row. His partner might blame him for this, but not make any modifications to his intentions and expectations. It is just too familiar by now. In addition to focusing on modifications to intentions and expectations, we may need to make room for the plausible idea that sometimes our existing intentions and expectations simply become more recalcitrant, in response to judgments of relationship-impairment. Perhaps our intentions and expectations can become more recalcitrant through a kind of reaffirmation (whether done consciously or not), in the sense that we modify certain higher-order intentions and expectations regarding existing first-order intentions and expectations. ${ }^{21}$ Perhaps the man blames his husband without making any modifications to his (first-order) intentions and expectations. It is nevertheless plausible that when the man judges his husband blameworthy, he reaffirms, or in some way maintains the intentions and expectations he originally formed in response to the impairment a number of years ago. I suggest something similar holds in cases of epistemic blame: sometimes, epistemically blaming others may partly consist in reaffirmations of certain intentions and expectations of others, made fitting by a judgment that they have done something to impair the GER.

What about blame in the absence of relationships? Imagine I somehow learn that someone who is otherwise completely sealed off from the epistemic community-call them

that the target of blame herself has of others: in some cases, we might understand the distinctively epistemic harm done by perpetrators of testimonial injustice in terms of failing to expect of a speaker that they will meet certain epistemic criteria, and thus failing to epistemically trust their word in a way that they should. This could be an importantly different way of impairing the GER. See Boult 2020 for discussion.

${ }^{21}$ Thanks to Adam Piovarchy for suggesting this possibility of higher-order intentions and expectations. See Scanlon $(2008,131)$ for similar discussion of a similar idea. 
Robinson Crusoe- - has engaged in some highly culpable epistemic conduct. Can I not epistemically blame Crusoe for his culpable epistemic conduct? ${ }^{22}$ The account appears to rule out this possibility. However, we must be careful here. For a start, keep in mind that the GER is a very thin notion of a relationship, one that is meant to hold between people in virtue of their status as epistemic agents (I return to this point in Section 6). So, it may not be the case that the account simply rules out the possibility of appropriately blaming Crusoe. But perhaps what seems odd about suggesting we stand in an epistemic relationship with Crusoe - even one as thin as the GER - is the fact that, as I understand the case, we know we'll never find ourselves relying on his word regarding anything. Again, he is simply sealed off from the epistemic community. For this reason, I am prepared to bite the bullet and disagree with those who would maintain it's appropriate to epistemically blame Crusoe. As long we stipulate that I do not stand in any active or even potentially active sort of epistemic relationship with the target of evaluation, then my view is that my evaluation of the target does not rise to the level of full-blown blame.

This is one occasion where the distinction between negative evaluation (including judgments of blameworthiness) and blame comes in handy. We can deploy it to assuage those who want to epistemically blame Robinson Crusoe. Careful reflection reveals that we can account for the intuition that he may be deserving of some form of criticism by allowing that he is the appropriate target of negative epistemic evaluation, and perhaps even judgments of epistemic blameworthiness.

This last point raises a new worry. If judgments of epistemic blameworthiness themselves are to be understood in terms of judgments that someone has done something to fall short of the normative ideal of the GER (even if they do not yet modify any intentions or expectations as a result), then it seems we are equally incapable of accommodating the idea that Crusoe is an appropriate target of a judgment of epistemic blameworthiness. After all, the idea behind the original worry is that Crusoe is not an active member of the GER. However, with a simple tweak we can accommodate this worry. We can do so by allowing that judgments of epistemic blameworthiness can include judgments that agents have done something that would impair the GER, were they to more actively stand in it with other members of an epistemic community. This helps make sense not only of Robinson Crusoetype cases but also of cases, for example, of judging that people in the distant past had attitudes or engaged in activities that were epistemically blameworthy. ${ }^{23}$

\footnotetext{
22 Thanks to an anonymous referee for pressing this worry.

${ }^{23}$ Scanlon makes a closely related point (Scanlon 2008, 146).
} 


\section{The Business Condition Revisited}

It flows naturally from a relationship-based approach to the nature of blame that when one does not stand in the relevant kind of relationship with another person, or if one's relationship with that person lacks the relevant significance, one may lack standing to blame that person for their actions or attitudes. This is a consequence of the fact that, according to the framework, blame consists in modifications or reaffirmations to the intentions and expectations that comprise our relationships with one another. The framework provides a natural explanation of why we should expect there to be a business condition on standing to blame. ${ }^{24}$ But how, more specifically, does my account of the nature of epistemic blame make sense of the business condition on standing to epistemically blame? The basic idea I want to flesh out and defend in this section is that another person's epistemic failing can be your business in virtue of the way it impairs your epistemic relationship with that person.

Return to The Office. Jim and Dwight are engaged in a practice of living up to (or failing to live up to) the intentions and expectations specified by the normative ideal of the GER. By forming (and maintaining) his conspiracy belief, in the absence of any evidence, Dwight fails to live up to the normative ideal of the GER. For example, he fails to meet an expectation of the form

- A expects, for any intellectual act X of B's, that B will meet epistemic criteria Y, unless B has good reason not to.

Perhaps he also reveals that he lacks an intention of the form

- B intends, for any intellectual act X of B's, to meet epistemic criteria Y, unless B has good reason not to.

According to my account, Jim's epistemic blame-response may amount to the judgment (however implicit) that Dwight has done something to impair the GER, plus a modification to his epistemic relationship with Dwight in a way made fitting by that judgment. For example, perhaps he modifies his intention to epistemically trust Dwight's word on matters in domain D under certain conditions.

Here is one way of specifying the sort of thing I have in mind in a bit more detail. Assume that prior to this particular incident, Jim's intentions to epistemically trust Dwight's word were broader in scope. That is to say, there were more items with respect to which he

\footnotetext{
${ }^{24}$ Scanlon discusses the virtue of his approach to blame that it readily explains intuitions about standing to blame $(2008,137)$. Interestingly, to my knowledge he does not discuss the business condition.
} 
was willing to epistemically trust Dwight. In response to the incident in question-more specifically, in response to Jim's judgment that Dwight has done something to impair the GER - the scope of Jim's intentions has narrowed.$^{25}$ There are now fewer items with respect to which Jim intends to epistemically trust the word of Dwight. Perhaps Jim simply reaffirms an existing intention with a particular scope, one that is more restricted than the normative ideal allows. Jim's negative attitudes towards Dwight in this regard simply become more recalcitrant. To represent this a bit more visually:

Let "domain D" be the domain of facts about office politics

Let " $\mathrm{d} 1-\mathrm{d} 5$ " specify more fine-grained sets of facts within that domain; for example, $\mathrm{d} 1$ = facts about boss Michael's interests $\mathrm{d} 2=$ facts about colleague Pam's interests $\mathrm{d} 3$ = facts about the executive's plans to downsize ....and so on...

Let "o" represent an empty set of facts

Let's say that at time t1, a subset of Jim's intentions to epistemically trust looks like this:

- Jim t1: epistemically trusts Dwight's word concerning range $<\mathbf{d 1}$...dn $>$ in domain D.

At t2, Dwight reveals his conspiracy belief to Jim. Jim forms the judgment that Dwight has done something to fall short of the normative ideal of the GER, and, as a result, his attitudes toward Dwight now look like this:

- Jim t2: epistemically trusts Dwight's word concerning range $<0>$ in domain D.

Jim went from intending to epistemically trust Dwight's word concerning $<\mathrm{d} 1$...dn $>$ to intending not to epistemically trust Dwight's word in domain D at all. This undoubtedly simplifies the sorts of changes that might occur in real life situations, but hopefully it makes the basic point vivid. The idea is to illustrate what it means to say that Jim modifies an intention to epistemically trust that is (partially) constitutive of the GER. Such a combination

\footnotetext{
${ }^{25}$ Perhaps it is more accurate to say that Jim has narrowed them — however, I would like to remain as neutral as possible on the question of precisely how much voluntary control we have over our blame responses.
} 
of judgment and modification to intentions and expectations just is what Jim's epistemic blame consists in.

We can readily see how Jim meets the business condition on standing to blame: he does so in virtue of the way his GER with Dwight has been impaired. That is to say, on my view, Dwight's epistemic failing is Jim's business precisely to the extent that, by manifesting this failing, Dwight falls short of certain expectations that Jim has of Dwight as a fellow member of the epistemic community. But this leads to an important issue. In order for Dwight's epistemic failing to count as Jim's business in this way, it is not enough that Dwight falls short of any old epistemic expectations that Jim has of Dwight. After all, people are free to irrationally expect anything they wish of anyone else. Crucially, Jim's expectations had better be ones he has legitimate claim to, or is in other words entitled to. ${ }^{26}$ Interestingly, there is a considerable degree of support in both ethics and epistemology for the idea that epistemic expectations, in some form-including in the very general way proposed in my account of the GER - are legitimate things for people to have of one another. The literature on culpable ignorance and moral responsibility is one place where support for this idea can be found (Moody-Adams (1994, 291); Rosen (2002, 79); and FitzPatrick (2008, 603, 612)). The literature on normative defeaters to knowledge and justified belief is another very different place where support can be found (Pollock (1986, 192); Meeker (2004, 162-163); Senor (2007, 207); Record (2013, 3, 8); and Miller and Record (2013,122, 124)). Sandy Goldberg's recent work on normative expectation is perhaps most explicitly aligned with my preferred approach here, so I will rely on some of his ideas in what follows. ${ }^{27}$

Goldberg $(2015 ; 2018)$ has argued at length in defense of the idea that people are entitled to have epistemic expectations of one another, simply in virtue of the fact that they are members of an epistemic community. He invokes the notion of a "practice generated entitlement". Many of our practices are such that they require us to have certain normative expectations of one another, in the sense that failure to have the relevant expectations would undermine the practice itself. According to Goldberg, in cases in which the practice itself is legitimate, one is entitled to such normative expectations. Perhaps the clearest examples of what Goldberg has in mind involve practices that structure our professional relationships, such as the doctor-patient relationship. That our family doctor is knowledgeable about the latest findings in the leading family medicine journals is a normative expectation we are entitled to have of our family doctors. To call into question such an expectation would be to

\footnotetext{
${ }^{26}$ Thank you to an anonymous referee for pressing this point.

${ }^{27}$ Goldberg himself points out that "there would appear to be some agreement among ethicists and epistemologists who think about related matters, to the effect that people are entitled to certain epistemic expectations regarding others" (Goldberg 2015, 5). He provides a helpful list of numerous authors in this regard, including those just mentioned, but also adds Montmarquet (1992, 336-337) and $(1999,845)$.
} 
call into question the practice itself: other things being equal, if you do not expect your family doctor to be reasonably informed about how to keep you healthy, then it is far from clear why you would rely on your family doctor to keep you healthy. Although this example involves an expectation that is epistemic in nature, it is just a specific instance of a much more general phenomenon. There are many plausible examples of practice-based entitlements beyond the epistemic domain (for instance, we are entitled to expect that others will drive on the correct side of the road).

How should we understand entitlements to expect that are not grounded in professional relationships? Here, Goldberg points out something I have already assumed, namely that we have a practice of relying on one another's say-so in a pervasive way for purposes of information-exchange and co-ordination. What Goldberg adds to this is the important point that such mutual reliance is practically rational for the parties involved. This is hard to deny. Living a life without the high level of epistemic dependence we have on one another would be incredibly cumbersome and even dangerous. But from this point, Goldberg plausibly concludes that this more general epistemic practice is indeed a legitimate one.

Most importantly for present purposes, the practice of relying on the word of others implies certain epistemic expectations. In relying on the word of someone else, for example, about where the nearest gas station is, you implicitly show that you normatively expect that, other things being equal, their word on such a matter is worth heeding, and, by extension, that the basic intellectual conduct of this person meets certain standards. ${ }^{28}$ Thus, practice generated entitlements come naturally to the surface here as well: calling into question your epistemic expectations of other members of your epistemic community would seem to require calling into question (in some form or another) the very practice of relying on their say-so in the pervasive way that it is practically rational for us to do. Since this general practice is practically rational for those involved, Goldberg maintains that it is legitimate. And since the practice is legitimate, the idea is that we are entitled to these epistemic expectations (Goldberg 2015, 18-19).

There is of course much more to say about the notion of a practice generated entitlement, as well any number of the assumptions at play in this argument for the claim that members of an epistemic community have an entitlement to expect of one another that they will meet certain epistemic criteria in conducting their intellectual lives. I cannot give a full

\footnotetext{
${ }^{28}$ Bear in mind that I am not committing myself to a view about what these epistemic criteria are. This is reflected in my use of a variable "Y" in spelling out some examples of the intentions and expectations constitutive of the normative ideal of the GER. Filling the details out is beyond the scope of this paper. One important, and likely complex, question is how practical stakes may have an impact on exactly which epistemic criteria we are entitled to expect others to meet. For example, might we be entitled to expect more as the stakes go up? This strikes me as plausible, but I will not pursue the matter here.
} 
defense of these claims here. But it is enough for present purposes to make the following conditional claim: if the foregoing story (or something similar) is plausible, then the relationship-based account of epistemic blame is poised to provide a general, detailed, and nuanced account of how the business condition can be met in the epistemic domain. Fruitful connections are readily visible between Goldberg's work on normative expectations and the intentions and expectations that are - according to the relationship-based account of epistemic blame - constitutive of our epistemic relationships with one another. There are promising avenues for future exploration here.

One might worry that this explanation of how the business condition can be met in the epistemic domain is somehow vacuous or trivial. That is to say, one might object that I have explained how the business condition can be met in terms of the idea of epistemic relationship impairment, but then maintain that my notion of an epistemic relationship simply amounts to "the thing that makes our mutual epistemic failings one another's business". ${ }^{29}$ However, this would be a mistake. For a start, this is not what my notion of an epistemic relationship amounts to. Rather, I have given independent support for the claim that, whether we are aware of it or not, most of us have expectations and intentions towards one another, simply in virtue of being parties to a mutually recognized practice of informational exchange and co-ordination-intentions and expectations that are thus oriented towards our epistemic agency in distinctive ways. Given my understanding of relationships as sets of intentions, expectations, and attitudes, these expectations and intentions partially constitute what I've called the GER. More than that, I have offered an account of why the epistemic expectations that partially comprise the normative ideal of the GER are ones we are entitled to have. So, there is a good deal of substantive theory underpinning my notion of an epistemic relationship - theory that can be articulated independently of any claims about the business condition.

There is, however, a second sense in which one might worry that the account I've offered is somehow vacuous or trivial. In particular, one might worry that an implication of my account is that everyone's epistemic conduct is one's business, and if everyone's epistemic conduct is one's business then this may seem to make the whole idea of a business condition on epistemic blame vacuous or incoherent. What's the point of condition on standing to blame that's always met?

In order to deal with this worry, I will emphasize two points. First, recall the degreeregulating conception of the business condition that I am working with. In Section 2, I defended the business condition in a more general context by arguing that it is more plausibly understood as a constraint on the degree or kind of blame it is fitting to direct towards

\footnotetext{
${ }^{29}$ Thanks to an anonymous referee for helpful comments here.
} 
someone, rather than a simple on-off switch determining a "yes" or "no" answer to the question of whether it is fitting to blame someone. The point in the present context is that such a condition can still have a point, even if it's true that everyone (or at least a very large number of people) meets it. And this is because people can meet the degree-regulating form of the business condition in different ways. Indeed, on a second but closely related note, in my view the GER is plausibly simply a kind of baseline for epistemic blame, to which a more realistic discussion must add details that arise when accounting for the nuances of all the other relations in which actual people stand in with one another. For example, in addition to the GER, people also stand in professional and institutional relationships, as well as a wide variety of personal relationships. Each of these relationships is structured by practices which generate more specific kinds of epistemic expectations (Goldberg 2018, 160-165). According to my account, modifications to intentions and expectations that partly comprise more specific kinds of relationships, but which are nevertheless oriented towards our epistemic agency in distinctive ways, may be part and parcel of more nuanced varieties of epistemic blame. The key point for present purposes is the following. Each of these more nuanced varieties will be constrained by the business condition, as understood on the degree-regulating conception. If you are a complete stranger who gives me faulty directions on the street, the specific form of epistemic blame it may be fitting for me to direct towards you will differ from the form that may be fitting for me to direct towards my family doctor for not reading up on the latest findings in the leading family medicine journals. ${ }^{30}$

I do not have the space here to develop a detailed account of how varieties of epistemic blame may differ across cases such as these. But here is a recipe for extending the relationship-based account of epistemic blame to encompass other kinds of cases, a recipe that offers a schematic basis upon which to begin developing the details of different forms of epistemic blame. Identify a general class of relationship, of which the case is an instance. Articulate the set of intentions and expectations that are directly relevant to the epistemic dimensions of the normative ideal of that relationship. That is, articulate the set of intentions and expectations that are oriented towards the cultivation or utilization of epistemic agency. Explain what it is that modifications to those intentions and expectations consists in, then show how the behaviors or practices characterized in the case are examples of such modifications. If, following Goldberg, we can also tell a story about why the relevant expectations are ones that parties to the relationship are entitled to have, then this is a recipe

\footnotetext{
${ }^{30}$ Here's another kind of example: in addition to the baseline, a critical thinking teacher's epistemic blame towards a student who repeatedly commits fallacy $\mathrm{x}$ despite the teacher's best efforts at showing them how to avoid committing fallacy $\mathrm{x}$ might also consist, partly, in intending to feel less enthusiastic about the student's future progress at avoiding fallacies in the future.
} 
not only for accounting in a unified way for what it is to epistemically blame someone in a wide range of cases, but also for explaining how the business condition can be met in each.

\section{Conclusion}

As noted earlier, it is increasingly common to find epistemologists theorizing about epistemic blame and relying on epistemic blame for other theoretical purposes. This prominence may be an upshot of the commonly held idea that there is a lot to be gained in our understanding of both epistemology and ethics by deepening our understanding of the way these two disciplines are related. There are disagreements about what this relationship consists in, but most philosophers agree that there are significant symmetries in the epistemic and moral domains. ${ }^{31}$ This appears to extend to the nature of our responses to one another for failings in these domains. In both cases, we seem to have a practice of responding to one another that goes beyond mere negative evaluation.

Indeed, in addition to the approach put forward here, Jessica Brown (2020) has recently defended a theory of epistemic blame by extending George Sher's (2006) influential theory of moral blame to the epistemic domain. Even more recently, Adam Piovarchy has challenged Brown's approach and defended his own "agency cultivation" model (Piovarchy forthcoming). It would be interesting to consider whether either of these accounts can as readily make sense of the business condition as the relationship-based account is poised to do.

It's also worth noting epistemic blame-talk is not just a feature of niche research programs in epistemology. It also features in central debates about epistemic justification. Consider: regardless of whether one is a radical externalist, a standard reliabilist, or an evidentialist about epistemic justification, it seems one must draw a distinction between justified and merely blameless belief in order to account for a diverse range of cases (Hawthorne \& Stanley 2008, 572; Boult 2019, 2017a, 2017b; Brown 2020, 4-5; Williamson forthcoming; Littlejohn forthcoming). If agents can be non-trivially blameless for their beliefs, then there are times when they are not blameless for their beliefs. This seems to imply that there can be something — blame_of which they are sometimes worthy. Thus, a central literature in epistemology appears to presuppose the idea that agents can be appropriately blamed, or worthy of blame, for their beliefs. ${ }^{32}$

\footnotetext{
${ }^{31}$ See Jason Baehr $(2011,206-222)$ for a helpful discussion of the options. Baehr's discussion is about the relationship between moral and intellectual virtue, but the structural points he makes can be generalized in useful ways. For a recent and forceful example of dissent on the idea that the epistemic domain is in important ways analogous to the moral domain, see Maguire and Woods (2020). ${ }^{32}$ As I discuss in Section 2, being blameworthy does not yet entail that one is actually an appropriate target of blame (for example, considerations about standing, or other instrumental considerations may undermine the appropriateness of blame). However, I regard the prominence of blamelessness/blameworthiness-talk in epistemology as defeasible evidence of the importance of epistemic blame for epistemology. One reason for this is that it would strike me as strangely pointless
} 
And yet, it is not immediately obvious how to make sense of epistemic blame in light of considerations about the business condition on standing to blame. The relationship-based account of epistemic blame provides tools for making this clear. Of course, and as I have noted, there are times when epistemic failings directly lead to the practical harm of other people (the Stephen case). In this limited way, it may seem obvious that epistemic failings can be the business of other people. But I have argued that more needs to be said before we can make sense of the fittingness of a genuinely epistemic kind of blame in such cases. I have also argued that there can be cases in which one person has the standing to epistemically blame another, despite the fact that no practical harm has been done, or when the practical harm is not itself what licenses the blame response (or when it is not the only feature of the case that makes a blame response fitting). The key to illuminating these kinds of case (I think The Office provides just one kind of example) is understanding them in terms of epistemic relationships. The concept of an epistemic relationship allows for a unified way of explaining a wide range of cases.

Many will find it unsurprising that the key to a better understanding of another central epistemic concept is to embrace a social approach to that concept. The relationship-based account of epistemic blame is ideally suited for this job. By making a key role for the notion of an epistemic relationship, the account provides a theoretical framework with which we can begin to make sense of an important dimension of our practice of epistemic blame - the dimension of standing. ${ }^{33}$

\section{References}

Boult, C. 2021. The significance of epistemic blame. Erkenntnis, online first.

Boult, C. 2020. There is a distinctively epistemic kind of blame. Philosophy and

Phenomenological Research, online first.

Boult, C. 2019. Excuses, exemptions, and derivative norms. Ratio, 32(2): 150-158.

Boult, C. 2017a. Epistemic normativity and the justification-excuse distinction. Synthese, 194(10): 4065-4081.

Boult, C. 2017b. Knowledge and attributability. Pacific Philosophical Quarterly, 98(1): 329350.

Baehr, J. 2011. The Inquiring Mind. Oxford: OUP.

to have a practice of judging people epistemically blameworthy if no one was ever an appropriate target of epistemic blame. One aim of the present project is to help make sense of how actual epistemic blame can be appropriate, in light of considerations about standing to blame.

${ }^{33}$ Thanks to audience members at a Social Epistemology Network Online, Social (Distance) Epistemology: Weekly Virtual Event, and audience members at the Philosophy Visiting Speaker Colloquium, University of Manitoba. Special thanks to Davide Fassio for comments on multiple drafts of this paper. 
Bell, M. 2013. The standing to blame: a critique. In Blame: Its Nature and Norms, Coates,

D.J \& Tognazzini, N.A (eds.). OUP: Oxord.

Brown, J. 2020. What is epistemic blame? Noûs, 54: 389-407.

Burge, T. 1979. Individualism and the mental. In Midwest Studies in Philosophy, IV, French,

Uehling \& Wettsteun (eds.). University of Minnesota Press.

Burge, T. 1986. Individualism and psychology. Philosophical Review, 95: 3-45.

Carter, J.A. \& Simion, M. 2020. The ethics and epistemology of trust. Internet Encyclopedia of Philosophy.

Chuard, P. \& Southwood, N. 2009. Epistemic norms without voluntary control. Noûs 43:4.

Coady, C.A.J. 1992. Testimony: A Philosophical Study. OUP: Oxford.

Dougherty, T. 2012. Reducing responsibility: an evidentialist account of epistemic blame.

European Journal of Philosophy, 20:4.

Dougherty, T. 2014. The ethics of belief is ethics (period). In The Ethics of Belief, OUP:

Oxford.

Feldman, R. 2004. The ethics of belief. In E. Conee and R. Feldman, Evidentialism. OUP:

Oxford.

FitzPatrick, W. 2008.Moral responsibility and normative ignorance: Answering a newskeptical challenge. Ethics, 118: 589-613.

Fricker, M. 2007. Epistemic Injustice. OUP: Oxford.

Fritz, K. \& Miller, D. 2018. Hypocrisy and the standing to blame. Pacific Philosophical Quarterly, 99:1

Harman, G. 1986. Change in View. MIT Press: Cambridge, MA.

Hieronymi, P. 2004. The force and fairness of blame. Philosophical Perspectives, 18:115-48.

Goldberg, S. 2018. To the Best of Our Knowlege: Social Expectations and Epistemic Normativity. OUP: Oxford.

Goldberg, S. 2010. Relying on Others: An Essay in Epistemology. OUP: Oxford.

Goldman, A. \& McGrath, M. 2014. Epistemology: A Contemporary Introduction. OUP: Oxford.

Goldman, A. \& Whitcomb, D. 2010. Social Epistemology: Essential Readings. (eds.) OUP: Oxford.

Hawthorn, J. \& Stanley, J. 2008. Knowledge and action. The Journal of Philosophy, 105:10.

Kauppinen, A. 2018. Epistemic norms and epistemic accountability. Philosophers' Imprint. 18.

Kelp, C. 2018. Good Thinking: A Knowledge First Virtue Epistemology. Routledge: London.

Littlejohn, C. Forthcoming. A plea for epistemic excuses. In The New Evil Demon: New Essays on Knowledge, Justification and Rationality, Dutant, J. (ed.), OUP. Oxford. 
Maguire, B. \& Woods, J. The game of belief. The Philosophical Review, 129: 211-249.

McCraw, B. 2015. The nature of epistemic trust. Social Epistemology 29: 413-430.

McHugh, C. 2012. Epistemic deontology and voluntariness. Erkenntnis 77.

Meeker, K. 2004. Justification and the social nature of knowledge. Philosophy and Phenomenological Research, 69: 156-172.

Miller, B., \& Record, I. 2013. Justified belief in a digital age: On the epistemic implications of secret internet technologies. Episteme, 10: 117-134.

Moody-Adams, M. 1994. Culture, responsibility, and affected ignorance. Ethics, 104: 91309.

Montmarquet, J. 1992. Epistemic virtue and doxastic responsibility. American Philosophical Quarterly, 29: 331-341.

Montmarquet, J. 1999. Zimmerman on culpable ignorance. Ethics, 109: 842-845.

Papineau, D. 2012. There are no norms of belief. In The Aim of Belief, Chan, T. (ed.). OUP: Oxford.

Peels, R. 2016. Responsible Belief: A Theory in Ethics and Epistemology. OUP: Oxford.

Pollock, J. 1986. Contemporary theories of knowledge. Maryland: Rowman and Littlefield.

Radzik, L. 2012. On the virtue of minding our own business. Journal of Value Inquiry, 46:2.

Radzik, L. 2011. On minding your own business: differentiating accountability relations within the moral community. Social Theory and Practice, 37:4.

Record, I. 2013. Technology and epistemic possibility. Journal for General Philosophy of Science, 28: 1-18.

Rettler, L. 2017. In defense of doxastic blame. Synthese, online first.

Rosen, G. 2002. Culpability and ignorance. Proceedings of the Aristotelian Society, 103: 6184.

Scanlon, T.M.1998. What We Owe to Each Other. Harvard University Press: Cambridge.

Scanlon, T.M. 2008. Moral dimensions: Permissibility, Meaning, Blame. Belknap Press: Cambridge, MA.

Senor, T. 2007. Preserving preservationism: A reply to Lackey. Philosophy and

Phenomenological Research, 74: 199-208.

Sher, G. 2006. In Praise of Blame, OUP: Oxford.

Smith, A. 2007. On being responsible and holding responsible. Journal of Ethics, 11:4.

Strawson, P. 1962. Freedom and resentment. In Proceedings of the British Academy, Vol. 48:

1962, G. Watson (ed.). OUP: Oxford.

Todd, P. 2017. A unified account of standing to blame. Noûs, 347-374.

Wallace, R.J. 1994. Responsibility and the Moral Sentiments. Harvard University Press.

Wallace, R.J. 2013. Dispassionate oppribrium. In Blame: Its Nature and Norms, Coates, D.J \& Tognazzini, N.A (eds.). OUP: Oxord. 
Williamson, T. forthcoming. Justifications, excuses, and sceptical scenarios. In The New Evil Demon: New Essays on Knowledge, Justification and Rationality, Dutant, J. (ed.), OUP. Oxford.

Wolf, S. 2011. Blame, Italian style. In R. J. Wallace, R. Kumar, \& S. Freeman (Eds.) Reasons and Recognition: Essays on the Philosophy of T. M. Scanlon (pp. 332-347). OUP: Oxford. 